\title{
Identifying Targets to Improve Antenatal Care for Substance Misuse in Pregnancy: An Observational Study
}

\author{
Richards $\mathrm{CE}^{1,2}$, Allman $\mathrm{M}^{1,2}$, Mann $\mathrm{M}^{1,2}$, Nandanan \\ $S^{1,2}$, Bennett $A^{3}$, Saunders $A^{1,2}$, Hildebrandt $T^{1}$, \\ Llewelyn $R^{2,4}$ and Margarit $L^{1,2,5 *}$ \\ ${ }^{1}$ Princess of Wales Hospital, Bridgend, UK \\ ${ }^{2}$ Neath Port Talbot Hospital, Port Talbot, UK \\ ${ }^{3}$ Dyfed Road Health Centre, Neath, UK \\ ${ }^{4}$ Singleton Hospital, Swansea, UK \\ 5Institute of Life Science, Swansea University, UK \\ *Correspondling author: Margarit L, Department of \\ Obstetrics and Gynaecology, Princess of Wales Hospital, \\ Bridgend, CF31 1RQ, UK
}

Received: April 05, 2021; Accepted: April 27, 2021; Published: May 04, 2021

\begin{abstract}
Background: Substance misuse in pregnancy contributes to increased maternal and fetal morbidity and mortality. Women who misuse drugs are, however, less likely to attend antenatal care. An observational study of the women who attended our substance misuse antenatal clinic was undertaken to identify targets for improving antenatal care for substance misuse in pregnancy derived from trends in maternal profiles, pregnancy outcomes and childhood consequences.
\end{abstract}

Methods: Data were retrospectively analysed from computer records and patient notes of the women who attended substance misuse antenatal clinic $(n=100)$ and children born from these pregnancies $(n=99)$.

Results: The women presented with complex heterogeneous substance misuse patterns. Attendance to the clinic was "good" in $73 \%$ with poor attendance in a sub-population with high alcohol use. Special care baby unit admissions ( $14 \%$ vs $6 \%, p=0.14)$ and length of hospital stay were greater than the non-substance misusing group $(5.3 \pm 7.4$ vs $1.2 \pm 1.3$ days, $p<005)$. More premature infants in the substance-misuse group had birth-weights less than the tenth centile $(86 \%$ vs $0 \%, p<0.05)$. At five years, a higher percentage of children in substance-misuse group had an ocular diagnosis compared with the control ( $22 \%$ vs $4 \%, p=0.0029)$, and increased social service involvement and out-of-home care.

Conclusions: We suggest better sexual health education for women in high-risk groups. This could be achieved by better integration between services. Antenatal care should target high-risk groups with earlier intervention and longer-term follow-up of children born to substance-misusing mothers.

Keywords: Substance misuse in pregnancy; Antenatal care; Paediatric ocular pathology

\section{Introduction}

Substance misuse disorders are commonly missed and undertreated among pregnant women, often because women who misuse substances fail to seek antenatal care early in pregnancy $[1,2]$. Moreover, a lack of antenatal care has been shown to further increase the likelihood of maternal and fetal morbidity and mortality in this cohort who are already at increased risk of negative perinatal outcomes [3]. Fear of negative repercussions and complex lifestyles stemming from widespread polydrug use, domestic violence, poverty and poor education are some of the deterrents to seeking antenatal care [4].

Expectant mothers with substance misuse disorders reported increased benefit from integrating substance misuse treatment with other services [5]. Nevertheless, research, policies, and guidelines are mainly focused on small-study, single interventions, that have proven ineffective on their own [6-10]. The growing epidemic of substance misuse in pregnancy highlights that there are multifactorial issues that remain unaddressed.

We retrospectively analysed the demographic and birth outcomes of a sample of pregnant women with a history of substance misuse and the five-year follow-up of children born from these pregnancies. Our aim was to identify knowledge gaps and trends in the population who engage with antenatal care to target the undertreated subpopulation and propose recommendations in their multifactorial care $[11,12]$.

\section{Methods}

This is a retrospective, single-centre study of all pregnant women who were misusing substance who were referred to our health board's Substance Misuse Antenatal Clinic (SMANC) between January 2012 and December 2013. All outcomes were compared to a reference group of pregnant women who attended the health board's midwifeled antenatal clinic in the same time period. The reference group comprised women who did not use prescribed or illicit substances or alcohol at their antenatal booking appointments.

Data were recorded on a standardised proforma from the All Wales Hand Held Maternity records and digital patient records on the Welsh Clinical Portal. Smoking status, alcohol consumption, and prescribed and illicit drug use during pregnancy were recorded on a self-reported basis in the All Wales Hand Held Maternity records and corroborated with urine toxicology analysis.

Social status was graded using the Index of Deprivation by
Austin J Obstet Gynecol - Volume 8 Issue 5 - 2021

Submit your Manuscript | www.austinpublishinggroup.com

Margarit et al. (C) All rights are reserved
Citation: Richards CE, Allman M, Mann M, Nandanan S, Bennett A, Saunders A, et al. Identifying Targets to Improve Antenatal Care for Substance Misuse in Pregnancy: An Observational Study. Austin J Obstet Gynecol. 2021; 8(5): 1180 


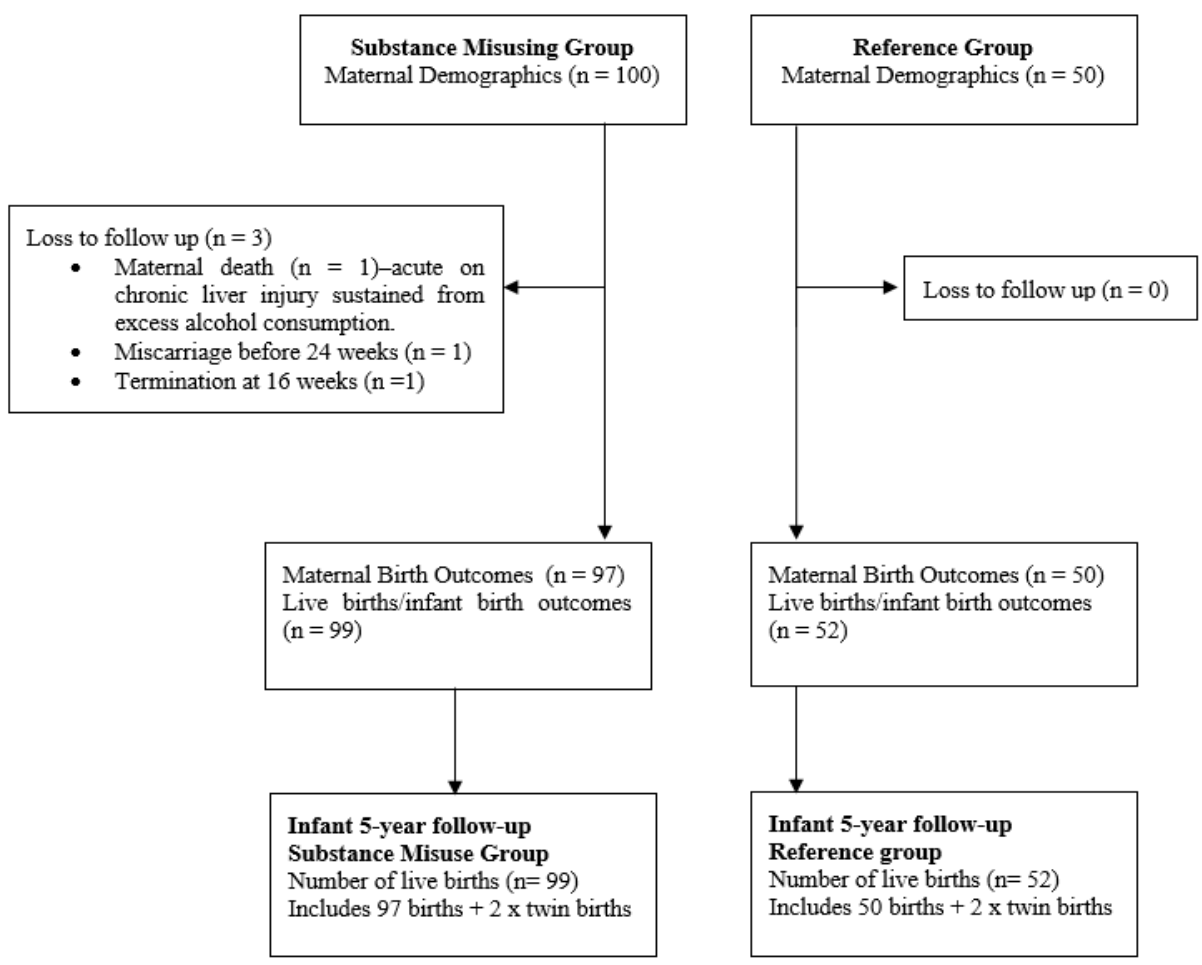

Figure 1: Flow Chart: Population Numbers for Maternal demographic, birth outcome and infants at 5-year follow-up.

postcode on a five-point scale ( $1=$ most deprived, $5=$ least deprived). To minimise confounding effects of social deprivation on outcomes, the reference group were matched via postcode to ensure the same distribution within each ordinal Index of Deprivation. Family status was based on whether the woman continued to be in a relationship with the child's father at the time of the birth. Routine Enquiry (RE1) into domestic abuse in the antenatal period is documented in the All Wales Maternity record. Attendance was classified as "good" if a minimum of $70 \%$ appointments were attended [3].

Birth outcomes and children born from these pregnancies were identified from the mother's digital birth records. Finnegan's Neonatal Abstinence Score, Special Care Baby Unit (SCBU) admission, length of hospital stay and feeding method at discharge were also recorded. Finnegan's Neonatal Abstinence Score tool is a 31 item scale designed to assess for the most common signs and severity of opioid withdrawal and guide appropriate treatment in the neonate if required [13]. Infant five-year follow-up data were then retrieved from the Welsh Clinical Portal. Follow-up information included social service involvement, separation from parents, developmental concerns, GP encounters and inpatient admissions.

\section{Statistical analysis}

Categorical variables were described as proportions and continuous variables were described as means. Significance between groups was assessed using the Chi squared test and the student t-test was used for analysis of continuous variables with normal distribution. A 2 -sided P-value $<0.05$ indicated statistical significance. Post-hoc power analysis and odds ratio were calculated using statistical software packages. (Matlab, version R2019b).

\section{Ethical approval}

Ethical approval was obtained from Abertawe Bro Morgannwg Research and Development review board prior to data extraction. At the time this service evaluation was undertaken, requirement for written informed consent was waived by the review board. Data extraction occurred prior to recent changes in Health Research Authority (HRA) and Health and Care Research Wales (HCRW) guidelines in April 2018 [14].

\section{Results}

Data were analysed from 100 consecutive women who attended SMANC and 50 women in the reference group between January 2012 and December 2013. Birth outcomes were assessed from children born from these pregnancies. The study flowchart in Figure 1 summarises recruitment, follow-up and analysis of each group.

A total was 99 live births (female 58\%, male 42\%) including two sets of twins (Mother/Child dyad, $\mathrm{N}=97 / 99$ ) were in the clinical group. All children were live born in the reference group, which also included two sets of twins, giving a final population of 52 infants (female 56\%, male 44\%; Mother/Child dyad, $\mathrm{N}=50 / 52$ ).

\section{Maternal characteristics and birth outcomes}

Maternal characteristics are summarised in Table 1. The substancemisuse group had a significantly higher gravida $(2.8 \pm 1.7$ vs $2.1 \pm 1.4$, $\mathrm{p}=0.013)$, fewer primiparous women ( $25 \% v s 44 \%, \mathrm{p}=0.018)$, a smaller mean maternal Body Mass Index (BMI) at antenatal registration (25.3 $\pm 4.8 \mathrm{~kg} \mathrm{~m}^{-2}$ vs $\left.28.0 \pm 5.3 \mathrm{~kg} \mathrm{~m}^{-2}, \mathrm{p}=0.0049\right)$, and a higher proportion of mothers who continued to smoke throughout pregnancy ( $76 \%$ vs $16 \%, \mathrm{p}<0.0001)$. 
Table 1: Maternal characteristics, and health and social status of substance misuse and reference group populations.

\begin{tabular}{|c|c|c|c|}
\hline & $\begin{array}{c}\text { Substance misuse } \\
\text { group } \\
(\mathrm{N}=100)\end{array}$ & $\begin{array}{c}\text { Reference } \\
\text { group } \\
(N=50)\end{array}$ & $p$-value \\
\hline Mean age at birth (years) & $27.2 \pm 6.0$ & $27.9 \pm 5.3$ & 0.49 \\
\hline Min-max & $17-44$ & $18-40$ & \\
\hline $\begin{array}{l}\text { Mean body mass index (kg } \\
\left.\mathrm{m}^{-2}\right)\end{array}$ & $25.3 \pm 4.8$ & $28.0 \pm 6.6$ & 0.0049 \\
\hline Min-max & $17-39$ & $17-44$ & \\
\hline Gravida & $2.8 \pm 1.7$ & $2.1 \pm 1.4$ & 0.013 \\
\hline Min-max & $1-9$ & $0-7$ & \\
\hline Parity & $1.3 \pm 1.4$ & $1.0 \pm 1.2$ & 0.1972 \\
\hline Min-max & $0-7$ & $0-5$ & \\
\hline Primiparous (\%) & 25 & 44 & 0.018 \\
\hline Smoking in pregnancy (\%) & 76 & 16 & $<0.0001$ \\
\hline Single parent (\%) & 32 & 2 & $<0.0001$ \\
\hline 1 & 20 & 11 & \\
\hline 2 & 21 & 7 & \\
\hline 3 & 20 & 10 & \\
\hline 4 & 20 & 11 & \\
\hline 5 & 19 & 11 & \\
\hline $\begin{array}{l}\text { Mental health diagnosis } \\
(\%)\end{array}$ & 39 & 24 & 0.0684 \\
\hline Schizophrenia & 3 & 0 & \\
\hline Depression & 13 & 11 & \\
\hline Bipolar & 6 & 0 & \\
\hline Anxiety & 6 & 1 & \\
\hline ADHD & 3 & 0 & \\
\hline Fetal alcohol syndrome & 1 & 0 & \\
\hline Multiple sclerosis & 1 & 0 & \\
\hline Chronic pain/back issues & 2 & 5 & \\
\hline Asthma & 1 & 8 & \\
\hline
\end{tabular}

The substance-misuse group had an increased incidence of mental health issues compared with the reference group (39\% vs $24 \%, p=0.0684)$. Twenty-one percent were prescribed psychiatric medications.

Drug and alcohol status is summarised in Table 2. Recreational drug use was categorised as single drug only (51\%), multiple drug (28\%), and drug and alcohol (16\%). Only 6\% of mothers attended SMANC for prescription of anti-psychotic medication alone while $15 \%$ of mothers were taking illicit substances in combination with their prescription anti-psychotic medication.

A significantly higher percentage of mothers were self-reported as single or separated from the infant's father at the time of birth in the substance misuse group ( $32 \%$ vs $2 \%, \mathrm{p}<0.0001)$. At least five women had disclosed a history of domestic abuse and were housed in sheltered accommodation as a consequence.

The birth outcomes of the substance misuse and reference groups are summarised in Table 3. Infants born to the substance-misuse group had a significantly lower mean birth weight $(3106 \pm 613 \mathrm{~g}$ vs
Table 2: Summary of alcohol status and prescribed and illicit substances in pregnancy.

\begin{tabular}{|c|c|}
\hline & $\begin{array}{l}\text { Substance Misuse Group } \\
\qquad(\mathrm{N}=100)\end{array}$ \\
\hline \multicolumn{2}{|l|}{ Illicit substances } \\
\hline Amphetamine & 15 \\
\hline Benzodiazepine & 15 \\
\hline Cannabis & 54 \\
\hline Cocaine & 11 \\
\hline MCAT & 7 \\
\hline Street Drugs & 4 \\
\hline Heroin & 11 \\
\hline Ecstasy & 1 \\
\hline Ketamine & 0 \\
\hline Alcohol in pregnancy & $25 \%$ \\
\hline Mean units/week & $320 \pm 1393$ \\
\hline Min-max & $0-7000$ \\
\hline \multicolumn{2}{|l|}{ Opiate Substitution Therapy } \\
\hline Methadone & 11 \\
\hline Subutex & 7 \\
\hline \multicolumn{2}{|l|}{ Analgesia } \\
\hline Co-codamol & 3 \\
\hline Tramadol & 1 \\
\hline Codeine & 3 \\
\hline \multicolumn{2}{|l|}{ Anti Psychotic medications } \\
\hline Quetiapine & 5 \\
\hline Mirtazapine & 5 \\
\hline Aripriprazole & 1 \\
\hline SSRI & 9 \\
\hline Risperidone & 1 \\
\hline Amitriptyline & 1 \\
\hline Haloperidol & 1 \\
\hline Methazepine & 1 \\
\hline Single illicit substance & 51 \\
\hline Multiple illicit substances & 28 \\
\hline Alcohol and illicit substances & 16 \\
\hline Anti-psychotics and illicit substances & 15 \\
\hline
\end{tabular}

$3459 \pm 554 \mathrm{~g}, \mathrm{p}=0.001)$ and mean head circumference $(33.8 \pm 1.6 \mathrm{vs}$ $34.9 \pm 1.5 \mathrm{~cm}, \mathrm{p}=0.000)$ compared with the reference group.

The proportion of preterm infants whose birth weight was on the $10^{\text {th }}$ centile or less was significantly higher in the substance-misuse group than the reference group ( $86 \% v s 0 \%, \mathrm{p}=0.0004)$. Nine-percent of term infants in the substance misuse group were on the $10^{\text {th }}$ birthweight centile or less.

Infants born to mothers in the substance-misusing group had a significantly longer hospital stay $(5.3 \pm 7.4 v s 1.2 \pm 1.3$ days, $\mathrm{p}=0.000)$ and $14 \%$ of infants required admission to the Special Care Baby Unit (SCBU). The population of infants with longer hospital stays 
Table 3: A summary of birth outcomes from the substance misuse and reference group populations

\begin{tabular}{|l|c|c|c|}
\hline \multirow{2}{*}{} & $\begin{array}{c}\text { Substance Misuse } \\
\text { Group } \\
\text { Sex of neonate }\end{array}$ & $\begin{array}{c}\text { Reference } \\
\text { Group } \\
\text { (N = 99) }\end{array}$ & \multirow{2}{*}{-value } \\
\cline { 2 - 4 } Female & $58 \%$ & $56 \%$ & 0.814 \\
\hline Male & $42 \%$ & $44 \%$ & 0.814 \\
\hline
\end{tabular}

\section{Gestational age (weeks)}

\begin{tabular}{|l|c|c|c|}
\hline Premature $(\leq$ week 37) & $15 \%(\mathrm{n}=14)$ & $12 \%(\mathrm{n}=5)$ & 0.615 \\
\hline Term (>week 37) & $85 \%(\mathrm{n}=83)$ & $88 \%(\mathrm{n}=45)$ & 0.615 \\
\hline $\begin{array}{l}\text { Mean birth weight } \\
\text { Premature weight }<10^{\text {th }} \\
\text { centile }\end{array}$ & $3106 \pm 613 \mathrm{~g}$ & $3459 \pm 554$ & 0.0007 \\
\hline $\begin{array}{l}\text { Term weight }<10^{\text {th }} \text { centile } \\
\text { Mean head circumference/ } \\
\text { cm }\end{array}$ & $86 \%$ & $0 \%$ & 0.0004 \\
\hline APGAR at 1 min & $93.8 \pm 1.6$ & $34.9 \pm 1.5$ & 0.0001 \\
\hline Mean & $8.3 \pm 1.5$ & $8.6 \pm 1.0$ & 0.196 \\
\hline \% Less than 7 & $15 \%$ & $12 \%$ & 0.614 \\
\hline APGAR at 5 min & & & \\
\hline
\end{tabular}

\begin{tabular}{|l|c|c|c|}
\hline \multicolumn{4}{|l|}{ APGAR at 5 min } \\
\hline Mean & $9.4 \pm 0.9$ & $9.5 \pm 0.6$ & 0.472 \\
\hline$\%$ Less than 7 & $4 \%$ & $0 \%$ & 0.145 \\
\hline $\begin{array}{l}\text { Cerebral imaging } \\
\text { indicated }\end{array}$ & $5(7 \%)$ & $2(4 \%)$ & \\
\hline Admitted to SCBU & $14 \%$ & $6 \%$ & 0.141 \\
\hline Length of hospital stay/days & & & \\
\hline Mean & $5.3 \pm 7.4$ & $1.2 \pm 1.3$ & 0.000 \\
\hline Min-max & $1-80$ & $0-7$ & \\
\hline
\end{tabular}

\begin{tabular}{|c|c|c|c|}
\hline \multicolumn{4}{|l|}{ Finnegan's score } \\
\hline \begin{tabular}{|l} 
Proportion with \\
Finnegan's
\end{tabular} & 20 & 0 & \\
\hline Mean & $5.7 \pm 4.3$ & 0 & \\
\hline Min-Max & $0-14$ & 0 & \\
\hline \multicolumn{4}{|c|}{ Medication support } \\
\hline Oramorph & $5 \%$ & $0 \%$ & 0.102 \\
\hline \multicolumn{4}{|c|}{ Feeding at discharge } \\
\hline Artificial & $88 \%$ & $62 \%$ & 0.0002 \\
\hline Breast & $12 \%$ & $38 \%$ & 0.0002 \\
\hline
\end{tabular}

\section{Mode of delivery}

\section{Caesarean section}

\begin{tabular}{|l|c|c|c|}
\hline Premature & $57 \%(n=8)$ & $40 \%(n=2)$ & 0.5248 \\
\hline Term & $20 \%(n=16)$ & $22 \%(n=10)$ & 0.7906 \\
\hline
\end{tabular}

\section{Spontaneous vaginal delivery}

\begin{tabular}{|l|c|c|c|}
\hline Premature & $36 \%(n=5)$ & $75 \%(n=3)$ & 0.3641 \\
\hline Term & $69 \%(n=56)$ & $74 \%(n=31)$ & 0.818 \\
\hline
\end{tabular}

\section{Instrumental}

\begin{tabular}{|l|c|c|c|}
\hline Premature & $0 \%$ & $0 \%$ & -- \\
\hline Term & $5 \%(n=4)$ & $9 \%(n=4)$ & 0.378 \\
\hline
\end{tabular}

coincided with $30 \%(n=20)$ of the neonates who were born to mothers who misused heroin and who were scored using the Finnegan
Neonatal Abstinence Scoring Tool with a mean score of $5.7 \pm 4.3$. Out of this sub-population, $20 \%(\mathrm{n}=4)$ were treated with oramorph for Neonatal Abstinence Syndrome (NAS). Mean APGAR scores at one and five minutes were similar for infants born to either group. At discharge, a higher proportion of children in the substance-misusing group were fed artificially compared with the reference group (88\% vs $62 \%, \mathrm{p}=0.000)$.

There were no statistical differences in the proportions of substance-misusing mothers requiring a cesarean section compared with the general population at term $(20 \%$ vs $24 \%, \mathrm{p}=0.598)$ or preterm (57\% vs 33\%, $\mathrm{p}=0.332$ ).

SMANC attendance was "good" in $73 \%$ of the population. In Table 4, maternal demographics and obstetric outcomes were compared between two sub-populations in the substance misuse group-those with "good" attendance and the remainder as "inadequate attendance". Mothers in the good attendance group had a significantly higher proportion of mental health issues compared to the inadequate attendees $(38.6 \%$ vs $12.2 \%, \mathrm{p}=0.011)$ and took a higher proportion of psychiatric medication $(26.8 \%$ vs $7.1 \%, \mathrm{p}=0.032)$. The inadequate group had a higher proportion of mothers who consumed alcohol during pregnancy ( $42.9 \%$ vs $18.3 \%, \mathrm{p}=0.012)$.

In the good attendance group, the mean gestational weight was greater compared to the inadequate attendance group (3148.0 vs $3005.1 \mathrm{~g}, \mathrm{p}=0.301)$, with fewer SCBU admissions ( $13.4 \%$ vs $18.5 \%$, $\mathrm{p}=0.526)$ and a reduction in mean length of hospital stay (4.6 vs 7.3 days, $\mathrm{p}=0.110$ ). Odds ratios demonstrate an increased likelihood of prematurity in inadequate attendees. While these differences were not statistically significant $(\mathrm{p} \neq 0.05$ and confidence intervals $<1$ ), they did demonstrate that attendance conveys a measureable difference.

\section{Five-year infant follow-up}

Table 5 summarises the child social and health outcomes over the five-year period following birth. Social services involvement was recorded for 33 infants while 31 infants were separated from the mother at birth, which included four adoptions. Where fiveyear follow-up data was available, $23 \%$ were recorded as having developmental concerns in the substance misuse group, which was significantly higher than the reference group infants $(23 \% v s$ $6 \%, p=0.011)$. The substance misuse group also had a significantly increased incidence of ophthalmology diagnoses compared with the reference $(21 \%$ vs $4 \%, \mathrm{p}=0.0061)$.

\section{Discussion}

Women who misuse substances during pregnancy are a high-risk group who are less likely to seek antenatal care [15]. Our maternal data and birth outcomes are consistent with other studies on substance misuse in pregnant women. Smaller average maternal BMI as well as illicit substance, alcohol and tobacco use have all been associated with increased likelihood of Small-for-Gestational-Age (SGA) infants [16-18]. Microcephaly [19], stillbirth18 19 and fetal alcohol spectrum disorders [22] are other reported negative outcomes.

Our study demonstrated good attendance to antenatal care in women with diagnosed mental health issues and taking psychiatric medication, indicating willingness by this sub-population to engage with the service throughout pregnancy. Attendance may therefore 
Table 4: A comparison of maternal demographic and obstetric outcomes between mothers with good SMANC attendance and poor or non-attenders.

\begin{tabular}{|c|c|c|c|c|c|}
\hline Characteristics & Good attendance & Inadequate attendance & $p$-value & Odds ratio $(95 \% \mathrm{Cl})$ & Post Hoc Power (\%) \\
\hline Number (Mother/child) & $68 / 69$ & $28 / 29$ & & & \\
\hline Maternal age & $26.7 \pm 6.3$ & $28.2 \pm 4.7$ & 0.2592 & & \\
\hline Maternal BMI & $25.3 \pm 4.5$ & $24.5 \pm 4.6$ & 0.4335 & & \\
\hline Smoker (\%) & 74.6 & 82.1 & 0.4313 & & 11 \\
\hline Alcohol (\%) & 18.3 & 42.9 & 0.0124 & & 70 \\
\hline Mental Health Issues (\%) & 38.6 & 12.2 & 0.0114 & & 76 \\
\hline Single illicit substance (\%) & 53.5 & 46.4 & 0.5291 & & 9 \\
\hline Multi-illicit substance (\%) & 28.6 & 28.6 & --- & & \\
\hline Psychiatric medication (\%) & 26.8 & 7.1 & 0.0323 & & 60 \\
\hline Gestational Age (weeks) & $39+4 / 40$ & $39+6 / 40$ & --- & & \\
\hline$<37$ weeks & 11 & 14 & 0.6812 & $1.49(0.49,4,93)$ & \\
\hline Gestational weight (g) & $3148.0 \pm 565.3$ & $3005.1 \pm 715.6$ & 0.3009 & & \\
\hline Prem $<10^{\text {th }}$ decile $(\%)$ & 75 & 100 & 0.2429 & $1.33(0.26,6.81)$ & \\
\hline Number of SCBU admissions (\%) & 13.4 & 18.5 & 0.5256 & & 11 \\
\hline Length of hospital stay (days) & $4.6 \pm 5.3$ & $7.3 \pm 11.1$ & 0.1096 & & \\
\hline APGAR 1 min & $8.3 \pm 1.4$ & $8.5 \pm 1.1$ & 0.5017 & & \\
\hline APGAR 5 min & $9.6 \pm 0.7$ & $9.3 \pm 1.1$ & 0.1128 & & \\
\hline Artificial feeding & $79.40 \%$ & 85.7 & 0.4747 & & 10 \\
\hline
\end{tabular}

Table 5: Summary of child health and social outcomes of children born to substance-misuse and reference groups at five-year follow-up.

\begin{tabular}{|c|c|c|c|c|c|}
\hline Child Outcome & $\begin{array}{l}\text { Substance Misuse Group } \\
\text { n (\%) }\end{array}$ & $\begin{array}{c}\text { Reference Group n } \\
(\%)\end{array}$ & $p$-value & Odds Ratio $(95 \% \mathrm{Cl})$ & Post Hoc Power (\%) \\
\hline \multicolumn{6}{|l|}{ Social Outcomes } \\
\hline Social service involvement & 33 & $1(2 \%)$ & & & \\
\hline Child removed/out-of-home care & $31^{\mathrm{a}}(39 \%)$ & $1(2 \%)$ & & & \\
\hline \multicolumn{6}{|l|}{ Health Outcomes } \\
\hline Full immunisation & $75^{\mathrm{b}}(86 \%)$ & $52(100 \%)$ & & & \\
\hline Mean number of GP visits/5 year (range) & $28.7 \pm 21.0(0-126)$ & $30.6 \pm 21.5(1-130)$ & 0.6024 & & \\
\hline Paediatric Assessment Unit/A \& E encounters & $0.8 \pm 1.0(0-4)$ & $0.6 \pm 0.8(0-3)$ & 0.2155 & & \\
\hline Paediatric ward encounters $/ 5$ years & $1.0 \pm 1.6(0-8)$ & $0.6 \pm 1.6(0-10)$ & 0.1479 & & \\
\hline Outpatient appointments $/ 5$ years & $2.6 \pm 3.9(0-17)$ & $2.4 \pm 3.3(0-16)$ & 0.7538 & & \\
\hline Developmental delayc ${ }^{c}$ & $16^{\mathrm{d}}(23 \%)$ & $3(6 \%)$ & 0.0206 & $4.7(1.3-17.0)$ & 66 \\
\hline Ophthalmology diagnoses ${ }^{e}$ & $19^{f}(21 \%)$ & $2(4 \%)$ & 0.0061 & $6.6(1.5-29.6)$ & 83 \\
\hline $\begin{array}{l}\text { Cardiac abnormalities-referred to specialist } \\
\text { cardiac unit }\end{array}$ & 2 & 0 & & & \\
\hline Atrial septal defect due to abilify (Aripriprazole) & 1 & 0 & & & \\
\hline Hepatitis B positive & 1 & 0 & & & \\
\hline
\end{tabular}

a19 unknown. Population $n=80$.

b10 unknown. Population $n=89$.

'Global delay and/or speech delay.

d27 unknown. Population $\mathrm{n}=72$.

eDiagnoses include: hypermetropia, esotropia, exotropia, amblyopia, astigmatism, convergent strabismus, broad epicanthus, pseudosquint.

f8 unknown. Population $n=91$.

be motivated by continued access to established interventions such as Opiate Maintenance Treatment (OMT) [23] and psychiatric or analgesic medication such as tramadol.

However, expectant mothers who misuse alcohol throughout pregnancy demonstrated inadequate attendance and may represent an even higher risk category as the one least likely to access care. In our study, this risk was highlighted by a miscarriage and subsequent maternal death due to acute alcohol-induced liver injury. Given that fetal alcohol spectrum disorders are the most common yet preventable cause of intellectual disability in infants, motivating attendance and 
addressing the specific needs of this group is all the more necessary [22].

We suggest that current targeted interventions are limited in identifying and addressing polydrug misuse and high-risk groups that receive late or no antenatal care. Idealising abstinence and recovery in UK substance misuse policies could be an added deterrent by setting unrealistic goals [24]. Furthermore, the focus of these policies and research on separate individual drugs leads to failure in addressing polydrug use. Such a narrow approach can also overlook those women who do not qualify for interventions such as OMT [23].

The higher gravida in our results may also give credence to the hypothesis that young girls who misuse substances are more likely to engage in risky behaviour, are less likely to use contraceptives or use them unreliably, and may use sex to finance their habit $[25,26]$. A higher percentage of expectant mothers were separated from the child's father. Where disclosed, a number of fathers were also recorded to misuse substances or had a history of domestic violence.

We recommend broader and more realistic policies and interventions to target polydrug and alcohol misuse, not just single substances. Booking and subsequent antenatal check-ups should systematically screen for polydrug use along with tobacco use and evaluate psychiatric history. Further consideration should be given to life circumstances through non-judgemental enquiries and appropriate documentation of domestic abuse or partner drug use [23].

Interventional programmes should involve a single location for combined services such as social services, midwifery, education and counselling, and coordination of care between primary care, psychiatry, obstetrics and gynecology, and mental health providers $[6,17,24,27-29]$. Scheduled appointments or community health visits with a specially trained staff member who can form a reciprocal and continuous working relationship could make a difference with the woman's engagement with the service.

Improving access to sexual health and contraceptive services could limit the number of unwanted pregnancies in this population. This could be integrated into holistic assessments when these women present in primary care or to drug and alcohol misuse agencies. Increased use of Long Acting Reversible Contraceptives should be considered when appropriate because of their lower failure rates.

At the five-year follow-up, there was an increased incidence of global developmental and speech delay and a significantly higher number of ocular diagnoses in children of the substance-misuse group [30]. Evidence of abnormal visual development continuing into mid-infancy following perinatal drug misuse is increasing. Reported ocular manifestations include nystagmus, strabismus, delayed visual maturation, lack of binocularity and reduced visual acuity [31].

Longer-term improvements in child outcomes are associated with stable care provision and early promotion of resilience and protective factors [2]. Professionals thus need to identify children at risk from perinatal drug exposure through non-judgemental support and intervention as soon as possible. Targeted interventions to improve immunisation rates are recommended as well as ophthalmology assessment in all these children under the age of five years.

\section{Limitations}

Despite its many outcomes, our study had some limitations. This was a single-centre study with a small population sample. However, from current literature and our demographic, we believe our study is representative of the typical low-income, substance-misusing population where polydrug use is a common alongside tobacco and alcohol use. The study design accounted for concomitant affects such as economic, financial and educational level by matching the substance misuse and reference groups for postcode and deprivation score. However, as well as differences in average age and BMI, mental health, psychiatric and domestic issues are added risk factors for poor perinatal outcomes.

Heterogeneous polydrug and alcohol misuse are also noted in other studies and generate added difficulties in correlating the effects of individual substances with obstetric and infant outcomes $[23,32]$. In this case, the small population size did not lend itself for multivariate analysis. Post-hoc power analysis demonstrated that the study is underpowered, especially in demonstrating significant effects between good and poor attendees. However, the initial study was not designed to measure size effects post intervention. As a service evaluation, the sample size was sufficient in comparison with outcomes of other similar population studies to identify local trends and knowledge gaps as a means of improving antenatal care in substance misuse [12]. The outcomes may also be subject to selection bias, as the sample was composed of women who attended at least one scheduled antenatal clinic and therefore represent the most motivated subpopulation of women with a history of substance abuse. Finally, every effort was made to collect a complete data set but this retrospective study was subject to attrition bias as a number of children were lost to follow-up.

\section{Conclusion}

Current interventional programmes remain too focussed on single issues and need to consider polydrug misuse and a range of connected health, social and domestic issues. Our data further identifies high-risk groups, in particular those with high alcohol consumption, who require increased motivation to attend antenatal care. Long-term biopsychosocial outcomes of children of substancemisusing mothers suggest a need for earlier intervention and longerterm follow-up with screening for ocular and developmental delays.

\section{References}

1. Behnke M, Smith VC. Prenatal substance abuse: Short- and long-term effects on the exposed fetus. Pediatrics. 2013; 131: e1009-e1024.

2. Gregory GA, Aiton NR. Intrauterine illicit drug exposure and neurodevelopmental outcomes for children: how current literature informs management and assessment. Paediatrics and Child Health. 2017; 27: 383387.

3. El-Mohandes A, Herman AA, El-Khorazaty MN, Katta PS, White D, Grylack L. Prenatal care reduces the impact of illicit drug use on perinatal outcomes. Journal of Perinatology. 2003; 23: 354-360.

4. Draper E, Gallimore I, Kurinczuk J, Smith P, Boby T, Smith L, et al. MBRRACEUK-Perinatal Mortality Surveillance Report (Jan-Dec 2017). 2018.

5. Marsh JC, Smith BD, Bruni M. Integrated substance abuse and child welfare services for women: A progress review. Children and Youth Services Review. 2011; 33: 466-472.

6. Lumley J, Chamberlain C, Dowswell T, Oliver S, Oakley L, Watson L. 
Interventions for promoting smoking cessation during pregnancy. Cochrane Database of Systematic Reviews. 2009.

7. Armstrong MA, Gonzales Osejo V, Lieberman L, Carpenter DM, Pantoja PM, Escobar GJ. Perinatal substance abuse intervention in obstetric clinics decreases adverse neonatal outcomes. Journal of Perinatology. 2003; 23 3-9.

8. Terplan M, Ramanadhan S, Locke A, Longinaker N, Lui S. Psychosocial interventions for pregnant women in outpatient illicit drug treatment programs compared to other interventions. Cochrane Database of Systematic Reviews. 2015.

9. Minozzi S, Amato L, Bellisario C, Ferri M, Davoli M. Maintenance agonis treatments for opiate-dependent pregnant women (Review ). Cochrane Database of Systematic Reviews. 2013.

10. Oei JL. Adult consequences of prenatal drug exposure. Internal Medicine Journal. 2018; 48: 25-31.

11. Moran P, Madgula R, Gilvarry E, Findlay M. Substance misuse during pregnancy; its effects and treatment. Fetal and Maternal Medicine Review. 2009; 20: 1-16

12. NICE. Pregnancy and complex social factors (CG110) A model for service provision for pregnant women with complex social factors. 2010.

13. Finnegan LP, Connaughton JF, Kron RE, Emich JP. Neonatal abstinence syndrome: assessment and management. Addictive Diseases. 1975; 2: 141 158.

14. NHS Health Research Authority. HRA Approval. 2020.

15. Uziel-Miller ND, Dresner N. Addressing substance abuse in obstetrics and gynecology. Primary Care Update for OB/GYNS. 2002; 9: 98-104.

16. Smith LM, LaGasse LL, Derauf $C$, Grant $P$, Shah R, Arria A, et al. The infant development, environment, and lifestyle study: Effects of prenatal methamphetamine exposure, polydrug exposure, and poverty on intrauterine growth. Pediatrics. 2006; 118: 11491156.

17. Chamberlain C, O'Mara-Eves A, Porter J, Coleman T, Perlen SM, Thomas $\mathrm{J}$, et al. Psychosocial interventions for supporting women to stop smoking in pregnancy. Vol. 2017, Cochrane Database of Systematic Reviews. 2017.

18. Sachs HC. The transfer of drugs and therapeutics into human breast milk: An update on selected topics. Pediatrics. 2013; 132

19. Garrison L, Leeman L, Savich RD, Gutierrez H, Rayburn WF, Bakhireva LN. Fetal growth outcomes in a cohort of polydrug- and opioid-dependent patients. Journal of Reproductive Medicine. 2016; 61: 311-319.
20. El Marroun H, Tiemeier H, Steegers E, Jaddoe V, Hofman A, Verhulst F, et al. Intrauterine Cannabis Exposure Affects Fetal Growth Trajectories: The Generation R Study. Journal of the American Academy of Child \& Adolescent Psychiatry. 2009; 48: 1173-1181.

21. Varner M, Silver R, Hogue CR, Willinger M, Parker C, Thorsten V, et al Association Between Stillbirth and Illicit Drug Use and Smoking During Pregnancy. Obstetrics \& Gynecology. 2014; 123: 113-125.

22. Senturias YSN. Fetal Alcohol Spectrum Disorders: An Overview for Pediatric and Adolescent Care Providers. Current Problems in Pediatric and Adolescent Health Care. 2014; 44: 74-81.

23. Reitan T. Patterns of polydrug use among pregnant substance abusers Nordic Studies on Alcohol and Drugs. 2017; 34: 145-159.

24. Chandler A, Whittaker A, Cunningham-Burley S, Williams N, McGorm K Mathews G. Substance, structure and stigma: Parents in the UK accounting for opioid substitution therapy during the antenatal and postnatal periods. International Journal of Drug Policy. 2013; 24: e35-e42.

25. Vella AM, Savona Ventura C, Wolff K. Pregnancy outcomes in substancemisusing pregnant women: A 10-year retrospective study. Journal of Obstetrics and Gynaecology. 2016; 36: 468-472.

26. Thangappah RBP. Maternal and perinatal outcome with drug abuse in pregnancy. Journal of Obstetrics and Gynaecology. 2000; 20: 597-600.

27. Manwell LB, Fleming MF, Mundt MP, Stauffacher EA, Barry KL. Treatment of problem alcohol use in women of childbearing age: Results of a brief intervention trial. Alcoholism: Clinical and Experimental Research. 2000; 24: $1517-1524$

28. Marshall R, Neher J. What effects-if any-does marijuana use during pregnancy have on the fetus or child? The Journal of Family Practice. 2017; 66: $462-464$

29. McLafferty LP, Becker M, Dresner N, Meltzer-Brody S, Gopalan P, Glance J et al. Guidelines for the Management of Pregnant Women With Substance Use Disorders. Psychosomatics. 2016; 57: 115-130.

30. Peragallo J, Biousse V, Newman NJ. Ocular manifestations of drug and alcohol abuse. Current Opinion in Ophthalmology. 2013; 24: 566-573.

31. Mactier $\mathrm{H}$. Neonatal and longer term management following substance misuse in pregnancy. Early Human Development. 2013; 89: 887-892.

32. Metz TD, Stickrath EH. Marijuana use in pregnancy and lactation: A review of the evidence. American Journal of Obstetrics and Gynecology. 2015; 213: 761-778 